\title{
Correction to: Impact of Ulnar Styloid Fractures on the Treatment Effect of Distal Radius Fractures with Volar Plate Fixation: A Case Control Study
}

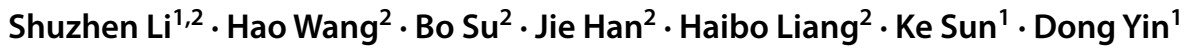

Published online: 13 March 2020

(c) Indian Orthopaedics Association 2020

\section{Correction to: \\ Indian Journal of Orthopaedics (2020) 54:75-82 \\ https://doi.org/10.1007/s43465-019-00016-2}

The original version of this article unfortunately contained a mistake. The Author Contributions were incorrect. The correct version is given below.

Author Contributions Conceived the design of the study: SL and BS. Performed the research: JH and HW. Analyzed the data: HL and KS. Contributed new methods or models: HW and HL. Wrote the paper: SL. Contributed equally to the study: SL and DY. Read and approved the content of the final manuscript: all authors.

The original article can be found online at https://doi.org/10.1007/ s43465-019-00016-2.

Dong Yin

tangin2002@163.com

Shuzhen Li

lishuzhenjoint@163.com

Hao Wang

825977211@qq.com; wanghaojoint@163.com

$\mathrm{Bo} \mathrm{Su}$

15877126379@qq.com

Jie Han

jham@163.com

Haibo Liang

1023582191@qq.com

Ke Sun

skgutou@163.com

1 Department of Orthopedic Surgery, The People's Hospital of Guangxi Zhuang Autonomous Region, Nanning 530021, China

2 Departmen of Orthopedic Surgery, The Affiliated Ruikang Hospital of Guangxi University of Chinese Medicine, Nanning 530011, China
Publisher's Note Springer Nature remains neutral with regard to jurisdictional claims in published maps and institutional affiliations.

\section{Springer}

